\title{
Ареалогическая структура флористического разнообразия Кодаро-Каларского оробиома
}

\section{Spatial distribution structure of the floristic diversity of the Kodar-Kalar orobiome}

\author{
Бочарников М. В. \\ Bocharnikov M. V. \\ Московский государственный университет имени М. В. Ломоносова, г. Москва, Россия. E-mail: maxim-msu-bg@mail.ru \\ M. V. Lomonosov Moscow State University, Moscow, Russia
}

Peфераm. В работе дана оценка пространственной организации флористического разнообразия Кодаро-Каларского оробиома через ареалогическую структуру высотно-поясных комплексов ценофлор. Использование высотных поясов и подпоясов растительности как ключевых структурных компонентов растительного покрова горных территорий в качестве опорных единиц анализа оробиома с учетом его высотно-поясной дифференциации, нашедшей выражение в географических вариантах оробиома, позволило на основе соотношения географических элементов флоры сосудистых растений выявить важнейшие черты географии его флористического разнообразия.

Ключевые слова. Ареал, оробиом, Северное Забайкалье, флористическое разнообразие, ценофлора.

Summary. The floristic diversity patterns of the Kodar-Kalar orobiome are discussed in this paper through the species spatial distribution structure on the basis of the altitudinal complexes of coenoflora. The structural components of mountain vegetation cover (altitudinal belts and sub-belts) are considered as the key units for the analysis of orobiome. The most important features of the geography of orobiome and its geographic variants floristic diversity are identified by species spatial distribution types.

Key words. Coenoflora, floristic diversity, Northern Transbaikalia, orobiome, spatial distribution.

\section{Введение}

Методологической основой исследования является биомная концепция оценки биоразнообразия, в соответствии с которой современная структура растительного покрова как базового компонента природных экосистем формируется в процессе адаптивного развития к эколого-географическим факторам (прежде всего, биоклиматическим показателям), находя выражение в преобладании определенных жизненных форм и их доминировании в фоновых сообществах. В условиях горных территорий эколого-географические закономерности формирования разнообразия биоты связаны с высотным градиентом и его интегральным выражением в структуре высотной поясности (Огуреева, Бочарников, 2017). Полные высотные спектры растительности как результат длительного эволюционного развития в трехмерной системе биогеографических координат (зональность, секторность и высотная дифференциация) характеризуются сопряжением связей между поясами в пределах спектра, что обуславливает их использование в качестве опорных единиц региональной оценки географии биоразнообразия и его картографирования (карта «Биомы России», 2018).

Флористический компонент ботанического разнообразия биомов выступает в качестве одного из ключевых показателей, характеризующих его региональную специфику. Выявленные связи дифференциации видового состава с высотным градиентом в горах (Куваев, Воропанов, 2005; Куваев, 2006), его сопряжение со структурой высотных поясов (Малышев, Пешкова, 1984) позволяют рассматривать флористическое разнообразие дифференцированно по поясам, что делает возможным проведение сравнительно-географического анализа разнообразия биоты гор в соответствии с биомными принципами 
ее региональной оценки на базе оробиомов. В данном понимании анализ проводится на основе видового разнообразия типологических подразделений растительности, составляющих фитоценотическое разнообразие. Узловым элементом выступает формация и соответствующая ей ценофлора как совокупность всех (за исключением редких) входящих в ее состав видов (Седельников, 1988). Объединения формаций в системе высотно-поясных подразделений растительного покрова образуют высотно-поясные комплексы ценофлор, рассматриваемые в работе в качестве опорных единиц оценки разнообразия биоты и эколого-географических факторов формирования ее пространственной структуры. Ареалогическая структура ценофлор послужила предметом исследования в силу важной роли географического анализа флоры в выявлении закономерностей формирования ботанического разнообразия, в том числе, горных территорий (Куминова, 1960; Положий, Крапивкина, 1971; Гаращенко, 1993).

\section{Материал и методы}

Ареалогический анализ высотно-поясных комплексов ценофлор Кодаро-Каларского оробиома проведен на основе выявленного с использованием литературных, гербарных и полевых данных флористического разнообразия (Бочарников, 2018). Высотно-поясные комплексы определены по видовому составу флоры сосудистых растений в пределах высотных поясов и подпоясов растительности, спектр которых характерен для оробиома (Bocharnikov et al., 2018). Связь видов с определенными высотно-поясными комплексами ценофлор определена на основе их высотного распространения в соответствии со всей занимаемой амплитудой по принципу «крайних пределов» (Юрцев, 1968). При недостаточно полной изученности как общего видового разнообразия, так и его высотной дифференциации в состав каждого из высотно-поясных комплексов ценофлор включены все виды с соответствующей высотной приуроченностью. Их ценотическая роль, выявляемая через активность в конкретных растительных сообществах поясов и подпоясов, которым соответствуют высотно-поясные комплексы, различна: они могут находить здесь оптимум своего развития либо произрастать на его высотном и экологическом пределе произрастания.

Теоретической основой проведения географического анализа комплексов ценофлор послужили представления об ареалах видов и геоэлементах флоры (Толмачев, 1962; Юрцев, 1968). В основу выделения ареалогических групп взята система, предложенная при анализе флоры Предбайкалья и Забайкалья (Малышев, Пешкова, 1984) с изменениями и дополнениями в связи с региональной спецификой распространения видов в области развития Кодаро-Каларского оробиома. Географическое распространение видов определяется широтными, меридиональными и, в горах, высотными закономерностями дифференциации биоты и условий среды. Это находит интегральное выражение в региональной специфике распространения видов через их единство в рамках ареалогических групп. Все разнообразие типов географического распространения видов, составляющих флористическое разнообразие Кодаро-Каларского оробиома, определило выделение 13 ареалогических групп: американо-азиатская, восточноазиатская, евроазиатская, евросибирская, голарктическая, маньчжуро-даурская, общеазиатская, охотская, североазиатская, северо-восточно-азиатская, центрально-азиатская, прибайкальско-забайкальская, южносибирская.

Разнообразие высотно-поясных комплексов ценофлор в растительном покрове Кодаро-Каларского оробиома определяется спектром поясов гольцово-подгольцово-горнотаежного типа поясности, представленного горнотаежным поясом лиственничных (Larix gmelinii (Rupr.) Rupr.) лесов и высокогорными (подгольцовый, горнотундровый и гольцовый) поясами, характерными для растительного покрова Байкало-Джугджурской природной области и, в частности, Забайкалья (Сочава, 1980; Огуреева, 1991). С высотной неоднородностью фитоценотических оптимумов фоновых сообществ поясов связана их дифференциация и выделение в пределах горнотаежного пояса нижнего подпояса лиственнично-сосновых и пихтово-кедрово-еловых лесов и верхнего подпояса лиственничных лесов, а в пределах подгольцового пояса - нижнего редколесного подпояса и верхнего кедровостланикового подпояса. Различия в высотно-поясных колонках определяют разнообразие географических вариантов оробиома, отражающих специфику структуры поясности (состав поясов, высотные пределы их распространения) в соответствии с региональными особенностями растительного покрова. Выделено три варианта - Северобайкальский, Патомский и Кодаро-Каларский (карта «Биомы России», 2018). 
Показатели абсолютного богатства каждой ареалогической группы и процентного соотношения в пределах высотно-поясных комплексов ценофлор послужили основой их сравнительно-географического анализа. Для всего оробиома и его географических вариантов дано сравнение ареалогической структуры комплексов ценофлор, соответствующих выделенным подпоясам на основе анализа преобладающих и специфических групп видов (по доли видов каждой из групп в общем флористическом разнообразии комплекса).

\section{Результаты и обсуждение}

Общее флористическое разнообразие Кодаро-Каларского оробиома определено в 1200 видов и подвидов сосудистых растений в составе шести выделенных высотно-поясных комплексов ценофлор (Бочарников, 2018). Положение оробиома в бореальной области определяет ведущую роль в видовом составе видов четырех групп: голарктической, евроазиатской, североазиатской и южносибирской, на которые приходится почти $2 / 3$ флористического разнообразия оробиома (табл.). Преобладающими по численности являются голарктические виды с обширным циркумбореальным распространением. К ним относится около $1 / 4$ всего видового разнообразия оробиома. Вклад голарктических видов в разнообразие каждого высотно-поясного комплекса примерно одинаков (максимальная доля - в кедровостланиковом подгольцовом комплексе, минимальная - в гольцовом). По абсолютному богатству голарктических видов выделяются горнотаежные комплексы (более 200 видов). Большая часть данных видов относится к бореальным и связана с ценофлорами горнотаежного пояса, и только менее 20 \% является высокогорными, характеризующими связи высокогорий Станового нагорья с Арктикой (Saxifraga nivalis L., Draba alpina L., Sibbaldia procumbens L.) и гипоарктическим ботанико-географическим поясом (Botrychium boreale Milde, Polemonium acutiflorum Willd. ex Roem. et Schult.). Преобладание видов с широким распространением характеризует принадлежность растительного покрова оробиома к типам поясности бореального класса (Огуреева, 1991).

Второй по количеству видов является евроазиатская группа (13\% от общего числа видов оробиома), причем разница в доли данной группы между комплексами ценофлор более существенна. Наибольший вклад в разнообразие они вносят в горнотаежные комплексы (155 видов), среди которых более половины не характерны для растительного покрова высокогорий, являясь по своей эколого-ценотической приуроченности таежными (Padus avium Miller, Cystopteris sudetica A. Br. Et Milde, Trisetum sibiricum Rupr.), степными и лесостепными (Onobrychis arenaria (Kit.) DC., Veronica incana L., Scorzonera austriaca Willd, Iris humilis Georgi). Наименьшая доля евроазиатских видов отмечается для гольцового комплекса.

Третьей по численности в оробиоме является североазиатская группа видов. Ее роль в высокогорных комплексах выше по сравнению с горнотаежными. Около 25 монтанных и арктоальпийских видов связаны с высокогорьями, произрастая по всей высотной амплитуде, занимаемой подгольцовым, горнотундровым и гольцовым поясами (Dryas punctata Juz., Minuartia arctica (Steven ex Ser.) Graebner), либо только в самой верхней части спектра (Potentilla elegans Cham. et Schlecht., Acomastylis glacialis (Adams) A. Khokhr.).

Близкие значения разнообразия имеет группа южносибирских видов. Она отражает флористические связи растительного покрова Северного Забайкалья и гор Южной Сибири, которые прослеживаются во всех высотно-поясных комплексах. В каждом из них доля видов составляет около 10-12 \%. Южносибирские виды по своей эколого-ценотической роли и высотной приуроченности разнородны. Это монтанные виды, входящие в состав разных комплексов (Bergenia crassifolia (L.) Tritsch, Thymus altaicus Klokov et Shost.), виды, связанные с ценофлорами горнотаежных комплексов (Viola mauritii Tepl., Saussurea controversa DC.), высокогорные виды, произрастающие в сообществах подгольцового, горнотундрового и гольцового поясов (Rhodiola quadrifida (Pallas) Fischer et Meyer, Veronica densiflora Ledeb.). Около 40 южносибирских видов являются степными и лесостепными (Astragalus austrosibiricus Schischkin, Carex sabulosa Turcz. ex Kunth, Smelowskia alba (Pallas) Regel и др.), произрастающими, преимущественно, в нижнем подпоясе горнотаежного пояса.

Виды остальных ареалогических групп имеют относительно небольшое участие (табл.). Их доля существенно варьирует не только в зависимости от высотно-поясного комплекса, но также в соответствии с региональными особенностями формирования флористического разнообразия. 
Таблица

Ареалогическая структура флористического разнообразия высотно-поясных комплексов ценофлор Кодаро-Каларского оробиома и его географических вариантов (виды и подвиды сосудистых растений)

\begin{tabular}{|c|c|c|c|c|c|c|c|c|}
\hline \multirow{5}{*}{ Ареалогические группы видов } & \multicolumn{8}{|c|}{ Флористическое разнообразие высотно-поясных комплексов } \\
\hline & \multicolumn{7}{|c|}{ Число видов } & \multirow{4}{*}{$\begin{array}{c}\text { \% от общего } \\
\text { числа видов } \\
\text { оробиома }\end{array}$} \\
\hline & \multicolumn{6}{|c|}{ Высотно-поясные комплексы ценофлор } & \multirow{3}{*}{ Оробиом } & \\
\hline & \multirow{2}{*}{ I } & \multirow{2}{*}{ II } & \multicolumn{2}{|c|}{ III } & \multicolumn{2}{|c|}{ IV } & & \\
\hline & & & III. & III.2 & IV.1 & IV.2 & & \\
\hline \multirow{2}{*}{ Американо-азиатская } & \multirow{2}{*}{5} & \multirow{2}{*}{54} & \multicolumn{2}{|c|}{57} & \multicolumn{2}{|c|}{59} & \multirow{2}{*}{86} & \multirow{2}{*}{7} \\
\hline & & & \multirow{2}{*}{\multicolumn{2}{|c|}{\begin{tabular}{|l|l}
53 & 48 \\
\multicolumn{2}{|c|}{35}
\end{tabular}}} & 54 & 44 & & \\
\hline \multirow{2}{*}{ Восточноазиатская } & \multirow{2}{*}{7} & \multirow{2}{*}{34} & & & \multicolumn{2}{|c|}{63} & \multirow{2}{*}{79} & \multirow{2}{*}{7} \\
\hline & & & 35 & 29 & 46 & 54 & & \\
\hline \multirow{2}{*}{ Евроазиатская } & \multirow{2}{*}{4} & \multirow{2}{*}{34} & & & & & 158 & 12 \\
\hline & & & 48 & 60 & 112 & 143 & 158 & 13 \\
\hline Евросибипская & 0 & 4 & & & & & 55 & 5 \\
\hline Евросиоирская & 0 & 4 & 9 & 14 & 42 & 52 & 35 & 3 \\
\hline Гопапктическая & 17 & 122 & & & & & 304 & 26 \\
\hline 1ОЛарктическая & 11 & 122 & 157 & 170 & 224 & 220 & 304 & 20 \\
\hline 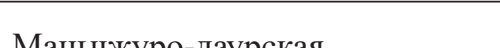 & 0 & 2 & & & & & 29 & 2 \\
\hline Мनанчжуро-даурская & 0 & 2 & 5 & 7 & 19 & 28 & 29 & 2 \\
\hline & & 0 & & & & & 35 & 3 \\
\hline Оощеазиатская & 0 & 9 & 11 & 14 & 20 & 28 & 35 & 3 \\
\hline Охотская & 0 & 1 & & & & & 19 & 2 \\
\hline OXUICкая & 0 & 1 & 4 & 9 & 17 & 19 & 19 & 2 \\
\hline Серепоариатсияс & 16 & 80 & & & & & 145 & 12 \\
\hline Североазиатская & 16 & 80 & 90 & 86 & 102 & 79 & 143 & \\
\hline Серепо-востошио-ариатсгея & 4 & 20 & & & & & 38 & 3 \\
\hline Северо-восточно-дзиатская & 4 & 20 & 22 & 18 & 27 & 22 & & \\
\hline Шентпапьио-ариатская & 4 & 14 & & & & & 32 & 3 \\
\hline Центрально-дзиатская & 4 & 14 & 14 & 10 & 6 & 18 & 32 & \\
\hline Прибайкальско-забайкальская & 11 & 41 & & & & & 75 & 6 \\
\hline 11риоаикальБско-заоаикалььская & 11 & 41 & 40 & 32 & 26 & 39 & 13 & 0 \\
\hline Южносибирская & 11 & 55 & & & & & 130 & 11 \\
\hline ГЖЖнОсИОИрекая & & $J J$ & 61 & 56 & 78 & 91 & 130 & \\
\hline Всего & 79 & 470 & & & & & 1185 & 100 \\
\hline & & & 54 & 553 & 773 & 837 & 1185 & \\
\hline
\end{tabular}

Примечание: высотно-поясные комплексы ценофлор: I - гольцовый; II - горнотундровый; III - подгольцовый (III.1 - кедровостланиковый; III.2 - редколесный); IV - горнотаежный (IV.1 - лиственничных лесов; IV.2 - лиственнично-сосновых лесов).

На основе географических вариантов оробиома дана оценка региональной специфики его ботанического разнообразия через ареалогическую структуру флоры высотно-поясных комплексов. На Северобайкальский вариант приходится более 90 \% видового разнообразия оробиома (около 1120 видов), 1/4 которого специфична для него. Это связано с повышенной долей южносибирских видов, участвующих в составе комплексов горнотаежного пояса, в нижнем подпоясе которого произрастают сообщества Урало-Южносибирской фратрии классов формаций (Сочава, 1980). Важную роль в увеличении видового богатства играет проникновение степных элементов (Leymus chinensis (Trin.) Tzvel. Stipa capillata L., Achnatherum sibiricum (L.) Keng ex Tzvelev), формирующих фрагменты реликтовых степей, которые локально встречаются в низкогорьях хребтов западнее долины реки Витим (Виппер, 1963). Преобладающая роль в структуре видового разнообразия сохраняется за голарктическими видами. В целом, ареалогическая структура видового состава комплексов ценофлор географического варианта 
сходна со всем оробиомом как для общего флористического разнообразия, так и для разнообразия каждого высотно-поясного комплекса.

Патомский вариант имеет относительно небольшое флористическое разнообразие (около 630 видов), составляющее около половины всего видового богатства оробиома. Флористическая специфика варианта выражена относительно слабо, в основном, за счет некоторых реликтовых видов неморального третичного комплекса, встречающихся в темнохвойных низкогорных лесах на севере нагорья (Botrychium multifidum (S. G. Gmelin) Rupr., Aconitum volubile Pall. ex Koelle). Специфика ареалогической структуры флористического разнообразия заключается в увеличении доли видов, имеющих евросибирское, евроазиатское и голарктическое распространение, а также в слабо выраженном эндемизме. Положение в северной части в системе нагорий Северного Забайкалья обуславливает снижение доли южносибирских и центрально-азиатских видов, преимущественно горностепных и высокогорных. Все эти черты с позиций флористического разнообразия характеризуют специфику растительного покрова Патомского нагорья (Русяева, 1979).

Кодаро-Каларский вариант по уровню видового разнообразия превосходит Патомский (всего около 720 видов). Специфичными для варианта являются 30 видов, многие из которых арктоальпийские элементы. В структуре флористического разнообразия по сравнению со всем оробиомом отмечается увеличение роли американо-азиатских видов, ряд которых входит в состав высотно-поясных комплексов ценофлор только данного варианта (Gentiana glauca Pall., Oxytropis nigrescens (Pallas) Fischer), а также североазиатских и голарктических видов. Флористический состав варианта отражает усиление связей с восточноазиатскими центрами формирования флоры, а также важную роль арктоальпийских и гипарктомонтанных элементов азиатского и американо-азиатского распространения в связи с развитием растительного покрова высокогорий хребтов Кодар, Калар, Удокан, занимающих значительную площадь (около $3 / 4$ всей области развития географического варианта).

\section{Заключение}

Проведенный сравнительный анализ ареалогической структуры флористического разнообразия высотно-поясных комплексов ценофлор Кодаро-Каларского оробиома показал важность использованных критериев оценки (видовой состав, соотношение типов географического распространения видов) для характеристики региональной специфики растительного покрова оробиома. Различия в ареалогической структуре флоры комплексов для разных географических вариантов оробиома относительно невелики. Вместе с этим они характеризуют важные эколого-географические особенности формирования биоты оробиома, пространственная организация которого находит через них свое выражение. Небольшое увеличение доли видов с тем или иным типом распространения отражает более тесные связи растительного покрова с крупнейшими центрами видообразования, характеризует специфику структуры высотно-поясных спектров растительности в рамках единой группы типов поясности и высотных пределов распространения поясов в соответствии с факторами их формирования.

Благодарности. Исследование выполнено за счет гранта Российского научного фонда (проект № 17-77-10142).

\section{ЛИТЕРАТУРА}

Бочарников М. В. Региональные черты в географии флористического разнообразия Станового нагорья // Проблемы ботаники Южной Сибири и Монголии. - Барнаул, 2018. - Т. 17. - С. 21-25.

Bunnep Б. П. Взаимоотношения леса и степи в юго-западной части Бурятской АССР // Материалы по изучению лесов Сибири и Дальнего Востока: Труды Института леса и древесины СО АН СССР. - Красноярск, 1963. C. 293-317.

Гаращенко А. В. Флора и растительность Верхнечарской котловины (Северное Забайкалье). - Новосибирск: ВО «Наука». Сибирская издательская фирма, 1993. - 280 с.

Карта «Биомы России» в серии карт природы для высшей школы. 2018. М. 1: 7500 000. Издание 2-е переработанное и дополненное / Г. Н. Огуреева, Н. Б. Леонова, Л. Г. Емельянова и др. - М.: Всемирный фонд дикой природы, 2018. 
Куваев В. Б. Флора субарктических гор Евразии и высотное распределение ее видов. - М.: Т-во научных изданий КМК, 2006. - 568 с.

Куваев В. Б., Воропанов В. Ю. Высотное распределение сосудистых растений в бассейне реки Большая Боотанкага (западная часть гор Бырранга, Таймыр) // Бот. журн., 2005. - Т. 90, № 5. - С. 633-653.

Малышев Л. И., Пешкова Г. А. Особенности и генезис флоры Сибири (Предбайкалье и Забайкалье). - Новосибирск: Наука, 1984. - 264 с.

Огуреева $\boldsymbol{\Gamma}$. Н. Ботанико-географическое районирование СССР. - М.: Изд-во Моск. ун-та, 1991. -78 с.

Огуреева $\boldsymbol{\Gamma}$. Н., Бочарников М. В. Оробиомы как базовые единицы региональной оценки биоразнообразия горных территорий // Экосистемы: экология и динамика, 2017. - Т. 1, № 2. - С. 52-81.

Куминова А. В. Растительный покров Алтая. - Новосибирск: Изд-во СО АН СССР, 1960. - 450 с.

Положий А. В., Крапивкина Э. Д. Географический анализ флоры черневой тайги Кузнецкого Алатау // Известия Сибирского отделения АН СССР. Сер. биол. наук., 1971. - Вып. 1, № 5. - С. 21-30.

Седельников В. П. Высокогорная растительность Алтае-Саянской горной области. - Новосибирск: Наука, 1988. - 222 c.

Сочава В. Б. Географические аспекты сибирской тайги. - Новосибирск: Наука, 1980. - 256 с.

Русяева $\boldsymbol{\Gamma}$. Г. Краткий очерк растительности центральной части Байкало-Патомского нагорья // Флора и растительность высокогорий. - Новосибирск: Наука, 1979. - С. 110-117.

Толмачев A. И. Автохтонное ядро арктической флоры и ее связи с высокогорными флорами Северной и Центральной Азии // Проблемы ботаники. - М.-Л.: Изд-во АН СССР, 1962. - Вып. 6. - С. 55-65.

Юрцев Б. А. Флора Сунтар-Хаята. Проблемы истории высокогорных ландшафтов северо-востока Сибири. Л.: Наука, 1968. - 235 с.

Bocharnikov M. V., Ogureeva G. N., Jargalsaikhan L. Regional features of the altitudinal gradients in Northern Transbaikalia vegetation cover // Geography, environment, sustainability, 2018. - Vol. 11, № 4. - P. 67-84. 